\title{
DIFICULTADORES NA FORMULAÇÃO DA POLÍTICA PÚBLICA DE SANEAMENTO BÁSICO EM MUNICÍPIOS GOIANOS
}

\author{
Gabriela Araújo Romão ${ }^{1}$ \\ Estela Najberg ${ }^{2}$
}

\begin{abstract}
RESUMO
Este trabalho pretendeu analisar os dificultadores na formulação da Política Pública de Saneamento Básico em municípios goianos na percepção dos atores governamentais e não governamentais. A estratégia utilizada foi o estudo comparativo de casos, tendo como foco de pesquisa os municípios de Pontalina, Itapirapuã, Mossâmedes e Uirapuru, que atenderam a dois requisitos: a conclusão dos seus respectivos Planos Municipais de Saneamento Básico e população inferior a 20 mil habitantes. Para a coleta de dados, foram feitas entrevistas semiestruturadas e o tratamento das informações coletadas ocorreu mediante análise de conteúdo. Desde o processo de elaboração do Plano Municipal de Saneamento Básico até a sanção da Política Pública de Saneamento nos municípios estudados, foram encontrados dificultadores, que podem ser agrupados em três eixos temáticos: comunicação; gestão municipal; participação e controle social. Entre os dificultadores encontrados, estão: a falta de quadro técnico especializado; dificuldade do município em aderir a programas de financiamento governamentais; descontinuidade administrativa; dificuldade em mobilizar a população para participar das audiências públicas, entre outros. Apenas o município de Itapirapuã não sancionou a Lei de Saneamento Básico.
\end{abstract}

Palavras-Chave: Formulação de Políticas; Políticas de Saneamento; Saneamento Básico; Plano Municipal de Saneamento Básico; Municípios Goianos.

\footnotetext{
${ }^{1}$ Mestra e doutoranda em Administração pela Universidade Federal de Goiás (UFG). E-mail: biromao@gmail.com ORCID: https://orcid.org/0000-0001-8098-0771

${ }^{2}$ Pós-doutora pelo Instituto Superior de Ciências Sociais e Políticas da Universidade de Lisboa (ISCSPULisboa). Doutora, mestra e graduada em Administração pela Escola de Administração de Empresas de São Paulo da Fundação Getúlio Vargas (EAESP-FGV). Professora associada da Universidade Federal de Goiás, atuando nos cursos de graduação e pós-graduação da Faculdade de Administração, Ciências Contábeis e Economia (FACE-UFG). E-mail: estelanaiberg@gmail.com ORCID: https://orcid.org/0000-0002-2852-4442
} 


\title{
DIFFICULTIES IN FORMULATING PUBLIC POLICY ON BASIC SANITATION IN MUNICIPALITIES OF GOIÁS
}

\begin{abstract}
This work aimed to analyze the difficulties in the formulation of the Public Basic Sanitation Policy in municipalities of Goiás in the perception of governmental and nongovernmental actors. The strategy used was the comparative study of cases, with the focus of research on the municipalities of Pontalina, Itapirapuã, Mossâmedes and Uirapuru, which met two requirements: the completion of their respective Municipal Basic Sanitation Plans and a population of less than 20 thousand inhabitants. For data collection, semi-structured interviews were conducted and the treatment of the collected information took place through content analysis. From the elaboration process of the Municipal Basic Sanitation Plan to the sanction of the Public Sanitation Policy in the studied municipalities, difficulties were found, which can be grouped into three thematic axes: communication; municipal management; participation and social control. Among the difficulties found, are: the lack of specialized technical staff; difficulty of the municipality in adhering to government financing programs; administrative discontinuity; difficulty in mobilizing the population to participate in public hearings, among others. Only the municipality of Itapirapuã did not sign the Basic Sanitation Law.
\end{abstract}

Keywords: Policy Formulation. Sanitation Policies; Basic Sanitation; Municipal Basic Sanitation Plan; Municipalities of Goiás.

\section{INTRODUÇÃO}

O Brasil é o quinto maior país do mundo em extensão territorial e possui a maior reserva de água doce superficial do planeta, dispondo em torno de $260.000 \mathrm{~m}^{3} / \mathrm{s}$ de água, o equivalente a $12 \%$ do total, o que se considera um imenso privilégio já que a população do país representa menos de $3 \%$ da população mundial (ANA, 2019). Todavia, diversos rios e mananciais deixam de ser utilizáveis, consequência, por exemplo, do despejo de efluentes sem tratamento adequado, da falta de serviço de coleta de esgoto, da ausência de gestão apropriada dos resíduos sólidos, além de leis que direcionem as responsabilidades sobre os recursos hídricos.

Dessa forma, uma solução, a longo prazo, é a universalização do saneamento básico, já que além de combater o mau uso da água, contribui para melhorar a 
qualidade de vida da população, evitando e erradicando doenças, além de impedir efeitos nocivos que possam prejudicar os indivíduos no seu bem-estar físico, mental e social.

Em 2007, foi sancionada a Lei Federal de Saneamento Básico (Lei no 11.445), que estabelece diretrizes nacionais e a política federal. Além disso, traz alento a uma área social que apesar de avanços, está distante do esperado, que é a universalização do seu acesso. Ainda conforme a Lei Federal de Saneamento Básico, a gestão dos seus serviços é repartida em quatro funções: o planejamento, a regulação, a fiscalização e a prestação de serviços, sendo todas as atribuições de responsabilidade do município; o planejamento é a única função indelegável. Cabe salientar que em 2020, foi sancionada a Lei no 14.026, que apresenta o novo marco legal do saneamento básico. Entre suas atribuições, estão a prorrogação para o fim dos lixões; a extinção do modelo atual de contrato entre municípios e empresas estaduais de água e esgoto, a viabilização de privatizações de estatais do setor, além de aprimorar as condições estruturais de saneamento básico proposto na Lei no 11.445/2007 (BRASIL, 2020).

No que tange as quatro funções da gestão dos serviços de saneamento, a regulação, do ponto de vista jurídico, trata da edição de normas específicas a cada setor. No caso da Lei no 11.445/2007, atribui à entidade reguladora as responsabilidades de apresentar normas referentes às dimensões econômica, técnica e social, que abrangem aspectos como: padrões e indicadores de qualidade da prestação dos serviços; medição, faturamento e cobranças de serviços; padrões de atendimento ao público e mecanismos de participação e informação, entre outros (BRASIL, 2007).

A fiscalização trata da aptidão das entidades fiscalizadoras em receber e se manifestar sobre contestações que não tenham sido atendidas pelos prestadores dos serviços, a partir da ótica do usuário (BRASIL, 2007). A prestação de serviços públicos de saneamento precisará obedecer às atribuições apresentadas nos planos municipais de saneamento básico, obedecendo aspectos como: programas, projetos e ações necessárias para atingir os objetivos e metas estipuladas no PMSB; 


\section{¿UNISUl}

diagnóstico da situação do saneamento e de seus impactos nas condições de vida da população atendida e objetivos de metas de curto, médio e longo prazos para a universalização do saneamento.

O planejamento do saneamento básico é constituído por etapas e o seu objetivo é a formulação e, posterior sanção da Política Pública de Saneamento Básico pelo município. A formulação da política municipal deve ocorrer por meio de preceitos estabelecidos no art. 9ำ da Lei nำ 11.445/2007 e no art. 23 do seu Decreto de Regulamentação no 7.217/2010 (BRASIL, 2007, 2010). O primeiro e principal preceito corresponde à elaboração do Plano Municipal de Saneamento Básico (PMSB), que deve abranger o conteúdo mínimo também estabelecido em lei. Após a sua elaboração, ocorrerá a sua aprovação, a aplicação por meio da execução e avaliação dos programas, projetos e ações previstos no plano, além de sua revisão, tendo como base a participação social (FUNASA, 2012). Ainda de acordo com a Fundação Nacional de Saúde (FUNASA), a partir dessas ações, o município deve apresentar o PMSB ao legislativo para aprovação e sanção de sua Política Pública de Saneamento Básico.

Os PMSBs são instrumentos fundamentais para o planejamento, porém, conforme o Panorama dos Planos Municipais de Saneamento Básico no Brasil, realizado no final de 2016 pelo Ministério das Cidades (MCidades), e que abrangeu $70 \%$ do total de municípios do país, apenas 30\% declararam possuir o plano (BRASIL, 2017). Este resultado pode ser explicado pela inexperiência concernente ao saneamento, além do fato de as prefeituras, em grande parte, não possuírem recursos humanos e técnicos para trabalhar nesta função. Dessa maneira, os municípios inclinam-se a contratar prestadores de serviços, o que pode desencadear numa situação cômoda à sua atuação, mascarando a realidade; ou contratar empresas, o que também tende a afastar a prefeitura e a comunidade no processo de elaboração, e consequentemente, de implementação da Política Pública de Saneamento (PEREIRA, 2012), contradizendo os princípios fundamentais estabelecidos na Lei no 11.445/2007, como o controle e a participação social. 
Os índices referentes ao saneamento básico no Brasil, e particularmente na Região Centro-Oeste e no Estado de Goiás, sobretudo, no que diz respeito à coleta e ao tratamento de esgoto, são preocupantes, já que em âmbito nacional, 46,9\% da população não têm acesso à coleta de esgoto, na Região Centro-Oeste este número sofre um pequeno aumento, alcançando 47,1\% e, no que tange o Estado de Goiás, $53,6 \%$ da população não têm acesso a este serviço. Em relação ao tratamento de esgoto, 46,3\% do esgoto nacional são tratados; na Região Centro-Oeste este número aumenta para 53,9\%, e no Estado de Goiás, apenas 49,6\% do esgoto passam por tratamento, ou seja, menos da metade da população goiana tem acesso à coleta e tratamento de esgoto, realidade muito distante da universalização de todos os setores que o saneamento básico preconiza (BRASIL, 2018a).

De acordo com o Instituto Brasileiro de Geografia e Estatística (IBGE), o Estado de Goiás ocupa uma área de $340.125,715 \mathrm{~km}^{2}$, sendo o sétimo do país em extensão territorial. A estimativa populacional de 2019 é de 7.018.354 milhões de habitantes, por conseguinte, é o Estado mais populoso do Centro-Oeste (IBGE, 2020). Goiás é constituído por 246 municípios; com base no Panorama dos Planos Municipais de Saneamento Básico desenvolvido pelo MCidades, em que foi utilizada uma amostra de $63,82 \%$ do total dos municípios do Estado, apenas 32 confirmaram a conclusão da elaboração do plano (BRASIL, 2017).

Dessa forma, procura-se neste trabalho, identificar e analisar os dificultadores na formulação da Política Pública de Saneamento Básico em municípios goianos na percepção dos atores governamentais e não governamentais. Foram selecionados 4 (quatro) municípios de Goiás, com base nos seguintes critérios: 1) que já tenha concluído o seu respectivo Plano Municipal de Saneamento Básico; 2) população inferior a 20 mil habitantes. Dessa forma, os municípios escolhidos foram: Pontalina, Itapirapuã, Mossâmedes e Uirapuru.

Nos próximos tópicos são apresentados os principais conceitos de políticas públicas, com ênfase em formulação de políticas, além do saneamento básico e as atribuições referentes ao plano municipal de saneamento básico. Em seguida, são exibidas a metodologia utilizada na pesquisa, a apresentação e discussão de 
resultados a partir das entrevistas semiestruturadas realizadas com atores governamentais e não governamentais dos municípios estudados e, por fim, as conclusões do trabalho.

\section{POLÍTICAS PÚBLICAS E FORMULAÇÃO DE ALTERNATIVAS}

Existem diversas conceituações para políticas públicas; de acordo com Sousa e Secchi (2015), política pública é uma entidade abstrata, que por meio de programas, obras, campanhas entre outros, transforma-se em instrumentos concretos. Souza (2006, p. 26), pontua que as políticas públicas na sua essência estão ligadas ao Estado e este determina como os recursos são usados para o benefício de seus cidadãos, além de afirmar que não há apenas uma definição de políticas públicas, mas que elas podem ser vistas como "um campo do conhecimento que busca, ao mesmo tempo, colocar o 'governo em ação' e/ou analisar essa ação (variável independente) e, quando necessário, propor mudanças no rumo ou curso dessas ações (variável dependente)".

No Brasil, o processo de políticas públicas passou por diferentes etapas, principalmente a partir da sanção da Carta Magna, em que as responsabilidades das políticas públicas sociais passaram do ente federativo para o ente municipal, modificando as estruturas de poder das subnacionais (ARRETCHE, 2002).

A descentralização do poder significou a participação social como fundamental para formular, executar e gerir ações; ou seja, o cidadão passou a ter mais força a partir do momento em que a esfera local obteve maior autonomia para desenvolver políticas públicas necessárias para os problemas específicos de sua localidade (BARBOSA, 2010). Cabe citar, porém, que tal descentralização não necessariamente garantiu eficiência na implementação das políticas, já que a autonomia dos governos locais necessita de administração eficiente e comprometida com as necessidades dos cidadãos (ARRETCHE, 2003).

Além disso, é fundamental que ocorra articulação colaborativa entre os entes federados, que de acordo com Dourado (2013) ocorre a partir dos dispositivos constitucionais, que devem tecer a dinâmica basilar do federalismo brasileiro e a 


\section{sunisul}

necessidade de cooperação e regulamentação entre o Governo Federal e as subnacionais.

Outro fator relevante no que diz respeito à eficiência ou não na implementação de políticas é a descontinuidade administrativa, que pode ser conceituada como paralisação de projetos e iniciativas, engavetamento de planos posteriores tendo como base viés político, sem considerar as qualidades das ações interrompidas (NOGUEIRA, 2006). Uma forma de tentar manter a continuidade política é garantir a participação popular no processo de mudança de gestão, já que a definição de prioridades nos investimentos dos recursos públicos mediante participação da população poderia ter como consequência continuidade de trabalhos, evitando, ainda, desperdício de recursos já investidos (LIMANA, 1999).

Uma maneira de entender o processo de política pública é fragmentá-la em fases interligadas, conjunto conhecido como ciclo de política pública (HOWLLET; RAMESH; PERL, 2013).

A formulação de alternativas é uma destas fases e pode ser definida como o processo de elaboração de escolhas para solucionar os problemas públicos. Nesta fase, ocorrem o reconhecimento e a formalização das opções políticas que terão como objetivo resolver os problemas definidos na fase de formação da agenda.

Vale salientar que há problemas complexos que demandam inúmeras alternativas para a formulação de políticas, como é o caso da Política de Saneamento Básico, cujos aspectos e especificações serão apresentados no próximo tópico.

\section{SANEAMENTO BÁSICO E A POLÍTICA PÚBLICA DE SANEAMENTO}

Em 2007, foram instituídas as diretrizes para o saneamento básico por meio da Lei ํㅜ 11.445, também conhecida como Lei Federal do Saneamento Básico (BRASIL, 2007) e no dia 3 de dezembro de 2008 foi aprovado pelo Conselho das Cidades (ConCidades) o Pacto pelo Saneamento Básico, que determinou o início da elaboração do Plano Nacional de Saneamento Básico (PLANSAB) que objetiva a universalização do saneamento no Brasil até 2033 (BRASIL, 2014). 


\section{sunisul}

No art. $3^{\circ}$, da Lei $\mathrm{n}^{\circ}$ 11.445/2007 o saneamento básico é definido como o conjunto de serviços, infraestruturas e instalações operacionais de: abastecimento de água potável; esgotamento sanitário; limpeza urbana e manejo de resíduos sólidos e drenagem e manejo das águas pluviais urbanas (BRASIL, 2007). A realidade brasileira apresenta problemas sérios em relação aos serviços de saneamento, fato caracterizado por um modelo econômico baseado em concentração de renda e infraestrutura, afetando diretamente os munícipios menos expressivos e as populações mais pobres, expondo-as a doenças infecto-parasitárias e baixo nível de condições sanitárias e ambientais (LISBOA; HELLER; SILVEIRA, 2013).

Além disso, de acordo com o Sistema Nacional de Informações sobre Saneamento (SNIS), os investimentos em água e esgoto no Brasil, no período de 2011 a 2017, sofreu progressiva diminuição, situação que dificultará a gestão sustentável de água e saneamento preconizada no PLANSAB (BRASIL, 2018b).

O principal preceito para a formulação da política pública de saneamento básico pelos municípios corresponde à elaboração do PMSB. Em 2012, a FUNASA, objetivando auxiliar os municípios, desenvolveu um termo de referência para elaboração de planos municipais de saneamento básico, em que são expostas, para a sua consolidação as fases para a elaboração do PMSB, quais sejam: 1) formação do grupo de trabalho; 2) plano de mobilização social; 3) diagnóstico técnicoparticipativo; 4) prospectiva e planejamento estratégico; 5) programas, projetos e ações; 6) plano de execução; 7) procedimentos para avaliação da execução do PMSB (FUNASA, 2012).

Após o cumprimento das sete fases, o município precisa apresentar o PMSB ao legislativo municipal para a sua aprovação e posterior definição da política pública de saneamento do município.

A Lei do Saneamento, em seu art. $2^{\circ}$, determina que os serviços públicos de saneamento básico sejam prestados com base nos seguintes princípios fundamentais da Lei no 11.445/2007: universalização do acesso; integridade; tecnologia apropriada; transparência das ações; intersetorialidade; integridade; controle social. (BRASIL, 2007, 2010). 


\section{sunisul}

A participação popular está fundamentada de maneira genérica no art. $1^{\circ}$ da Constituição Federal, que institui que o Brasil é regido por uma democracia indireta e de maneira especifica no art. 225, caput, da nossa Lei Maior, que cita o dever de toda a coletividade e do Poder Público atuarem na defesa e proteção ao meio ambiente, tendo como base de complementariedade a educação e informação ambiental (VASCONCELOS, 2002).

Assim sendo, outro aspecto relevante no processo de participação popular é a educação ambiental que pode ser conceituada como educação política, já que incorpora as relações econômicas, sociais, culturais e políticas entre a humanidade e o meio ambiente, tendo como objetivo o aumento da cidadania, da autonomia e da intervenção dos cidadãos na busca de soluções para o bem comum (REIGOTA, 2017). Na mesma linha de raciocínio, Jacobi (2003) discorre a respeito da importância da educação ambiental no processo de sensibilização, informação e formação de cidadãos ambientalmente participativos e responsáveis. Tais conceitos sintetizam os objetivos da educação expostos pela Carta de Belgrado, em 1975, que também cita a produção de conhecimentos referentes à ecologia, com o objetivo de conscientizar e sensibilizar os indivíduos a participarem efetivamente na solução e prevenção de problemas ambientais.

De acordo com a Funasa (2014), existe um importante elo entre saneamento básico e educação ambiental, já que além de obras de infraestrutura e tecnologias, um complexo processo educativo deve existir para conscientizar as pessoas e, essas, por sua vez, transformarem seu entorno.

Apesar de poucos estudos na área de políticas de saneamento básico, algumas pesquisas apontam dificultadores para que a elaboração dos PMSBs ocorra conforme estabelecido em lei, como a sua incompatibilidade com a capacidade técnica e gerencial do município; as dificuldades na nomeação de membros que formarão os comitês; a escassez de quadros qualificados para a sua elaboração; a tendência em considerar o PMSB como mais um documento de gaveta, entre outros (QUEIROZ, 2014). Dessa forma, tanto a elaboração como a execução dos PMSBs enfrentam complexos desafios, situação que deverá ser enfrentada e superada pelos municípios. 


\section{¿UNISUl}

No trabalho publicado por Lisboa; Heller e Silveira (2013), são apresentadas, na percepção de gestores municipais representando 15 municípios de pequeno porte do Estado de Minas Gerais, as principais dificuldades que os municípios enfrentam em relação ao planejamento do saneamento básico, tendo como foco a elaboração do plano municipal de saneamento básico, e corroborando com a apresentação de Queiroz (2014), os resultados foram: a indisponibilidade de recursos financeiros e a limitação quanto à qualificação profissional e capacidade técnica municipal.

Já Alves Filho (2016), apresenta o panorama situacional dos planos municipais de saneamento básico nos municípios do Rio Grande do Norte, e analisa, por meio de uma categoria específica, quais foram as principais dificuldades dos municípios no que diz respeito ao processo de elaboração do PMSB. Os resultados são compatíveis com os apresentados por (LISBOA; HELLER; SILVEIRA, 2013; QUEIROZ, 2014), isto é, falta de recursos financeiros e equipe técnica não qualificada. Outro dificultador apontado por Alves Filho (2016) refere-se à relação direta entre problemas de saúde pública e a falta de educação ambiental e mobilização social dos cidadãos. Além da falta de vontade política no processo de elaboração do PMSB, apesar de este aspecto não ter sido claramente percebido pelos municípios.

\section{MÉTODO}

O método de pesquisa adotado neste estudo é o qualitativo, que se caracteriza em propiciar dispersão, profundidade aos dados, contextualização do ambiente, detalhes e experiências únicas (SAMPIERI; CALLADO; LUCIO, 2013), características estas aderentes ao presente trabalho. A estratégia utilizada é o estudo comparativo de casos, uma vez que a pesquisa analisa a formulação da política pública de saneamento de quatro municípios diferentes, que se caracterizam por peculiaridades específicas. Tilly (1989) expõe que o estudo comparativo de casos permite, mediante exploração das diferenças e semelhanças, constatar os princípios de mudança de padrões e fenômenos em um grau maior de concepção. 


\section{¿unisul}

No que tange à coleta de dados, a fim de mapear os municípios que já elaboraram seus respectivos PMSBs, foi feita uma pesquisa prévia por meio de sítios eletrônicos de prefeituras municipais, ministérios e secretarias responsáveis pelo setor de saneamento básico no Brasil, como por exemplo: a Secretaria Nacional de Saneamento Ambiental (SNSA); o Instituto Brasileiro de Geografia e Estatística; o Sistema Nacional de Informação sobre o Saneamento entre outros. Mediante tais informações, foram escolhidos os quatro municípios pertencentes ao Estado de Goiás que tiveram seus PMSBs e suas respectivas formulações das Políticas Públicas de Saneamento Básico analisados. Cabe ressaltar que os requisitos para a escolha dos municípios se deu por meio de dois fatores: 1) ter concluído a elaboração do PMSB e 2) população inferior a 20.000 habitantes.

O primeiro requisito se explica pelo fato de que a formulação da política pública só ocorrerá após a conclusão da elaboração do PMSB, por conseguinte tal exigência se torna imprescindível para o cumprimento do objetivo deste trabalho. O segundo requisito justifica-se pelo fato de o Estado de Goiás ser constituído de municípios que apresentam, em sua maioria, baixa densidade demográfica, já que dos 246 municípios pertencentes ao Estado, 191 possuem população inferior a 20 mil habitantes, situação semelhante ao restante do país, em que a maior concentração populacional encontrase nas capitais e zonas litorâneas (IBGE, 2020). Estes municípios, não raro, possuem vastas extensões territoriais face ao número reduzido de habitantes, o que dificulta a sustentabilidade do município já que os recursos arrecadados não conseguem suprir as suas necessidades; deficiência em infraestruturas, desde falta de hospitais, até estrada para acesso em zonas mais afastadas; ausência de corpo técnico qualificado; ineficiência administrativa; falta de emprego para os jovens, entre outros (SOARES, 2008). Dessa forma, os municípios estudados neste trabalho são: Pontalina, Itapirapuã, Mossâmedes e Uirapuru.

Após a escolha dos municípios, foram feitas entrevistas semiestruturadas com atores governamentais e não governamentais que participaram diretamente do processo de elaboração do PMSB. Cabe citar que as entrevistas foram gravadas a partir do consentimento dos respectivos entrevistados. No Quadro 1 são expostos os 


\section{sunisul sim}

atores entrevistados, o órgão em que trabalhavam e o cargo que ocupavam no período de elaboração do PMSB.

Quadro 1 - Atores entrevistados

\begin{tabular}{|c|c|c|c|c|c|c|}
\hline \multirow[b]{2}{*}{ Município } & \multicolumn{3}{|c|}{ Atores não governamentais } & \multicolumn{3}{|c|}{ Atores governamentais } \\
\hline & Órgão & Cargo & $\begin{array}{c}\text { Relação com } \\
\text { a elaboração } \\
\text { do PMSB }\end{array}$ & Órgão & Cargo & $\begin{array}{c}\text { Relação com } \\
\text { a elaboração } \\
\text { do PMSB }\end{array}$ \\
\hline Pontalina & $\begin{array}{c}\text { Empresa } \\
\text { de } \\
\text { Consultoria } \\
1\end{array}$ & Diretora & Coordenadora & $\begin{array}{c}\text { Secretaria do } \\
\text { Meio } \\
\text { Ambiente }\end{array}$ & $\begin{array}{l}\text { Secretária } \\
\text { do Meio } \\
\text { Ambiente }\end{array}$ & $\begin{array}{c}\text { Coordenadora } \\
\text { Municipal }\end{array}$ \\
\hline Itapirapuã & $\begin{array}{c}\text { Empresa } \\
\text { de } \\
\text { Consultoria } \\
1 \\
\end{array}$ & Diretora & Coordenadora & $\begin{array}{c}\text { Departamento } \\
\text { de Controle } \\
\text { Interno }\end{array}$ & $\begin{array}{l}\text { Diretor de } \\
\text { Controle } \\
\text { Interno }\end{array}$ & $\begin{array}{l}\text { Executor } \\
\text { Municipal }\end{array}$ \\
\hline Mossâmedes & $\begin{array}{l}\text { Empresa } \\
\text { de } \\
\text { Consultoria } \\
2\end{array}$ & $\begin{array}{c}\text { Engenheira } \\
\text { ambiental }\end{array}$ & Coordenadora & $\begin{array}{c}\text { Secretaria do } \\
\text { Meio } \\
\text { Ambiente }\end{array}$ & $\begin{array}{l}\text { Secretária } \\
\text { do Meio } \\
\text { Ambiente }\end{array}$ & $\begin{array}{l}\text { Executora } \\
\text { Municipal }\end{array}$ \\
\hline Uirapuru & $\begin{array}{c}\text { Empresa } \\
\text { de } \\
\text { Consultoria } \\
2 \\
\end{array}$ & $\begin{array}{c}\text { Engenheira } \\
\text { Ambiental }\end{array}$ & Coordenadora & $\begin{array}{l}\text { Gabinete do } \\
\text { prefeito }\end{array}$ & $\begin{array}{c}\text { Assessor } \\
\text { do } \\
\text { Prefeito }\end{array}$ & $\begin{array}{l}\text { Executor } \\
\text { Municipal }\end{array}$ \\
\hline
\end{tabular}

Fonte: Autoras.

Foram produzidos dois roteiros de entrevista. O primeiro, direcionado aos atores não governamentais e constituído por onze questões, abarcaram os seguintes pontos: os possíveis dificultadores no processo de elaboração do PMSB em cada uma das sete fases necessárias para a consolidação do plano; como se deu a parceria entre o município e a empresa de consultoria e o prazo estipulado e utilizado para a 
conclusão do PMSB. O segundo roteiro, desenvolvido para os atores governamentais e composto por cinco questões, buscaram responder indagações relacionadas a participação do município no processo de sanção da Lei Federal de Saneamento Básico; os possíveis dificultadores na parceria firmada entre município e consultoria no processo de elaboração do PMSB, além dos desafios no processo de sua formulação no que diz respeito às sete fases estipuladas para a sua consolidação; as respectivas ações desenvolvidas pelo município após a conclusão do PMSB; e se o município sancionou a sua política municipal de saneamento básico.

O tratamento dos dados ocorreu a partir do método de análise de conteúdo, (BARDIN, 2016). Na pré-análise, foram consultados os PMSBs e foi feito o check list referente à análise dos outros preceitos da formulação da Política de Saneamento. Para a análise, interpretação e discussão dos resultados, os autores lançaram mão do software Nvivo.

\section{APRESENTAÇÃO E DISCUSSÃO DOS RESULTADOS}

A partir das entrevistas com os atores governamentais e pesquisas nos portais das Câmaras Municipais dos quatro municípios estudados, foi verificado que Itapirapuã foi o único que não sancionou a Política Municipal de Saneamento Básico. Vale dizer que não há exigência em lei desta ação e nem prazo determinado para sua aprovação.

Esta seção procura identificar e analisar os dificultadores no processo de elaboração do PMSB, bem como nas ações desenvolvidas pelos municípios antes da sanção das políticas públicas de saneamento básico. Os dificultadores estão expostos mediante três eixos temáticos: comunicação; gestão municipal; participação e controle social.

\section{Comunicação:}

A partir das entrevistas semiestruturadas com os atores governamentais dos municípios estudados, verificou-se que nenhum deles participaram da fase de formulação da Política Federal de Saneamento Básico, apenas de discussões posteriores, quando a lei já havia sido sancionada, o que denota a falta de 
comunicação e articulação entre os níveis federativos. Tal dificultador demonstra que apesar de a Carta Magna garantir dispositivos que dinamizam e estabeleçam a importância de cooperação e comunicação entre os entes federados (DOURADO, 2013), tal situação não ocorreu de forma plena.

Outro agravante encontrado no eixo comunicação refere-se ao desenvolvimento de relatórios correspondentes ao diagnóstico urbano e rural dos municípios. Os dois atores não governamentais relataram dificuldades em acessar dados municipais de responsabilidade da prestadora de serviço de saneamento, como exposto pela diretora da Consultoria 1, responsável pelo auxílio na elaboração dos PMSBs de Pontalina e Itapirapuã:

\begin{abstract}
Muitas vezes a SANEAGO demorava para informar os relatórios de análise da situação atual, além disso, há também uma certa dificuldade entre os órgãos dos distritos com o órgão da regional de Goiânia e quem informa para nós todos os dados de água e esgoto, quando há essa concessão é a regional de Goiânia.
\end{abstract}

Tal situação está relacionada com outro dificultador, que é a falta de um banco de dados municipais com informações atualizadas sobre o saneamento básico local. De acordo com a representante da Consultoria 1:

\begin{abstract}
No diagnóstico geral, da zona urbana, eu falo que principalmente os detalhes que não são assumidos pela SANEAGO né, não se sabe como que se dá a necessidade da drenagem pluvial, não tem conhecimento desses dados (...)eles não têm conhecimento de nada, isso dificulta muito o trabalho, eles não têm esse cadastro de informações baseado na prefeitura (...).
\end{abstract}

Tal problema aponta para a não consumação do princípio fundamental da integralidade, que tem como objetivo propiciar à população o acesso à conformidade de suas necessidades, mediante máxima eficácia e eficiência de resultados (BRASIL, 2007). A partir do momento em que o município não possui informações atualizadas sobre a própria situação dos componentes do saneamento, não conseguirá cumprir os objetivos estabelecidos na lei (HELLER, 2010; MORAES, 2009).

A ausência de um banco de dados atualizados também se contrapõe a outro princípio fundamental exigido em lei - a transparência de ações, que estabelece que 


\title{
sunisul
}

o município disponha de sistemas de informações atualizados para a população (BRASIL, 2007).

\section{Gestão Municipal:}

Verificou-se que todos os municípios estudados necessitaram abrir licitações para a escolha das consultorias, tendo como motivo principal a falta de quadro técnico especializado para planejar e dar continuidade à elaboração do plano sem apoio. A falta de quadro técnico especializado corresponde a um dos principais dificultadores no processo de elaboração dos planos, já que na maioria dos casos, os municípios brasileiros não possuem funcionários com as qualificações necessárias, até mesmo, para compor os comitês de saneamento básico (QUEIROZ, 2014), situação também exposta na pesquisa desenvolvida por Lisboa et al. (2013).

A falta de recursos técnico-financeiros com a finalidade de utilizar sistemas mais eficientes e sustentáveis nos municípios representa mais um dificultador no processo de elaboração e implementação do PMSB, conforme relato do ator não governamental da Consultoria 1:

\begin{abstract}
A gente tenta apontar que não existe, por exemplo, tratamento de água somente a filtração ou filtro russo ou para o tratamento de esgoto só tem as lagoas de estabilização, a gente mostra que tem outras coisas, mas infelizmente, são características, ordens técnicas que a gente mostra que tem, mas que infelizmente esses governos não têm capacidade de arcar com um tratamento desses.
\end{abstract}

Esta fala vai ao encontro dos resultados discorridos nos trabalhos de Lisboa et al. (2013), Queiroz (2014) e Alves Filho (2016) que apontaram como fator dificultador na implementação dos planos a falta de recursos técnico-financeiros. Além de corroborar com a importância da tecnologia apropriada, um dos princípios fundamentais citados na Lei $\mathrm{n}^{0}$ 11.445/2007, que trata, entre outras coisas, da visualização dos rumos tecnológicos a longo prazo, (BRASIL, 2014).

Outro agravante mencionado pela Diretora da Consultoria 1, corresponde à aplicabilidade das medidas estruturantes de gestão ao longo do tempo, como apontado a seguir:

[...] e também outras questões, campanha de educação ambiental, esses programas estruturantes em si, então a gente está desenvolvendo dessa 
forma, mas se vai ser aplicado? Dificilmente vai, porque a gente percebe que secretariado hoje, eles estão é, eles andam muito unidos assim, eles não sabem ao certo de quem é a responsabilidade de quem, (...).

Esse dificultador expõe a importância da eficiência na gestão, e corrobora com a informação citada por Arretche (2003), que chama a atenção para a descentralização do poder a partir da Constituinte de 1988, em que se acreditava que com a autonomia, principalmente dos municípios, em gerir as políticas públicas formuladas pelo governo federal, se atingiriam melhores resultados, o que nem sempre acontece.

$O$ ator não governamental da Consultoria 1 também expõe 0 problema referente à capacidade do município em aderir a programas de financiamento governamentais, como relatado abaixo:

Nós temos uma burocracia muito grande, ainda mais agora que nós não temos mais o programa de aceleração de crescimento né, o PAC, tem outros programas, outros convênios com o BNDES, outras agências de fomento, mas a burocracia é muito grande, por exemplo, para você poder instalar um aterro, você já precisa ter um projeto pronto, de onde que vem o dinheiro para você contratar uma consultoria?

O relato corresponde com as informações expostas pelo Sistema Nacional de Informações sobre o Saneamento (SNIS), que apresentou uma diminuição progressiva dos investimentos em saneamento, fato que tende a dificultar a gestão sustentável de água e saneamento preconizada no PLANSAB (BRASIL, 2018a). Tal cenário diminui consideravelmente as chances de os municípios resolverem os problemas advindos da falta de infraestrutura, e expõe as populações mais pobres a doenças infecto-parasitárias e precárias condições sanitárias e ambientais (LISBOA; HELLER; SILVEIRA, 2013).

A inaptidão municipal em aplicar os indicadores expostos no PMSB, aliada à baixa capacidade de manutenção do que está sendo desenvolvido com o apoio técnico da consultoria ao término do contrato de parceria, foi outra dificuldade apresentada pela Diretora da consultoria 1 , como relatado a seguir:

É, avaliação sistemática eu acho que é uma das partes mais complexas do plano e que eu acho que está ali para encher linguiça, porque o que acontece, a gente desenvolve esses indicadores só para fazer essa avaliação sistemática do que está funcionando e do que não está em relação a todas 
as ações, programas e projetos desenvolvidos aí ao longo dos vinte anos do plano, só que assim, será que os programas, esses projetos e ações serão realmente executados?

Esta situação remete a Queiroz (2014) e a Alves Filho (2016) quando os autores apresentam a importância de se manter um corpo técnico permanente no município, e que a sua falta tende a gerar, em consequência, o engavetamento do PMSB.

Pode-se afirmar, enfim, que a capacitação técnica dos agentes responsáveis pela gestão do saneamento é fundamental ao seu bom funcionamento, independentemente das mudanças de gestão ao longo do tempo, situação esta que pode gerar a descontinuidade administrativa, a qual, de acordo com Nogueira (2006) interrompe programas, projetos, obras e dependendo da radicalidade das mudanças político-administrativas trazidas pela nova gestão, leva ao engavetamento de planos futuros. Tal contexto foi vivenciado pelo município de Pontalina, a partir do relato da secretária do meio ambiente a respeito das ações municipais preliminares à sanção da política de saneamento:

\footnotetext{
A única coisa que teve depois do plano, que a gente implantou e que está no plano, é a coleta seletiva né, que a gente está tentando implantar, mas assim, fora isso, gaveta. Elaborou só para cumprir uma lei né, nada mais.
}

A partir dos dificultadores apresentados neste eixo temático, compreende-se a importância da gestão municipal para o prosseguimento das ações necessárias para a conclusão das metas e objetivos estabelecidos nos PMSBs; outro aspecto imprescindível é a participação popular.

\section{Participação e Controle social:}

A falta de conhecimento da população em relação aos componentes do saneamento interferiu no desenvolvimento e progresso do tema nas audiências públicas, como relatado pelo ator governamental do município de Uirapuru:

A dificuldade às vezes é que como o nosso município é pequeno, que tem menos de 10 mil habitantes, às vezes o pessoal não vê tanta prioridade em saneamento básico, porque aqui o pessoal nunca usou e também não tem conhecimento para poder buscar, então a maior dificuldade foi trazer a dificuldade que poderia ter, para montar o plano, buscar as ações para eles poderem executá-lo né no município depois de implantado. 
De acordo com a Diretora da Consultoria 1, a falta de compreensão da população e dos gestores municipais em relação aos problemas que só serão resolvidos a longo prazo, foi um fator limitante nas audiências públicas, como apresentado abaixo:

Todo mundo percebe que água é crucial né, então o primeiro eixo do saneamento básico que estabelece é a água, só que o que acontece eles querem água ao mesmo tempo que querem esgoto, que querem coleta de lixo, gerenciamento correto de resíduos sólidos e drenagem pluvial, nós temos um eixo do Plano de Saneamento de vinte anos, mas eles querem que tudo seja resolvido no prazo de cinco e seis anos no máximo, (...).

Os atores governamentais e os não governamentais foram unânimes em reconhecer a falta de interesse da população em participar das audiências públicas. Como relatado pelo assessor do prefeito do município de Uirapuru:

Como sempre, o principal dificultador é você conseguir fazer com que as pessoas se deslocassem das suas casas, dos seus trabalhos para chegar até o local onde eram feitas essas ações, essas audiências né.

E reforçado pelo ator não governamental dos municípios de Pontalina e Itapirapuã:

A gente vê que a população lá reclama muito, mas ela não quer participar. $E$ a gente percebe também que quando a gente vai, por exemplo, instalar tarifa de coleta de lixo, eles já reclamam, eles acham que a tarifa, ela não é necessária, que o município consegue arcar com essas despesas.

O baixo nível de participação e de controle social aponta para a importância da educação ambiental no processo de sensibilização, informação e formação de cidadãos ambientalmente participativos e responsáveis (JACOBI, 2003).

Limana (1999) aborda a relevância da participação popular para garantir, ao menos em parte, a continuidade dos programas, projetos e ações vistos como prioridades, diminuindo, dessa forma, os possíveis impactos advindos de uma possível mudança de gestão no município. Citação que está de acordo com Barbosa (2010) e Carvalho (2006), que ao discorrerem sobre a municipalização também exprimem a valia da participação dos cidadãos no desenvolvimento local.

Vale citar que as autoras deste trabalho enviaram ao Senado Federal, valendose da Lei de Acesso à Informação (LAl), questionamentos referentes à participação da sociedade na formulação da Política Federal de Saneamento e a resposta obtida 


\section{sunisul}

foi: "[...], quanto à participação social, não houve audiências públicas e nem opinião de consulta pública". Tal informação contraria a Constituição Federal de 1988, que definiu o país como um Estado Democrático de Direito, em que o novo modelo de gestão pública traz a participação popular como um pilar da cidadania, além de um ato decisivo de exercício de poder.

Também contradiz o próprio Decreto de Regulamentação da Lei do Saneamento, que cita como ferramentas dessa instância "I - debates e audiências públicas; II - consultas públicas; III - conferências das cidades; ou IV - participação de órgãos colegiados de caráter consultivo na formulação da política de saneamento básico, bem como no seu planejamento e avaliação" (BRASIL, 2010).

Tal situação demonstra que apesar de a Lei ํㅜ 11.445/2007 exigir do ente municipal recursos de mobilização para que todo o processo de elaboração de sua Política Pública de Saneamento ocorra com a participação popular, a formulação da lei federal ocorreu de maneira antagônica às suas próprias resoluções.

No Quadro 2, são apresentados os dificultadores municipais a partir dos três eixos temáticos:

Quadro 2 - Dificultadores municipais

\begin{tabular}{|c|l|l|}
\hline Município & Eixo Temático & \multicolumn{1}{c|}{ Dificultador } \\
\hline \multirow{7}{*}{ Pontalina } & Comunicação & $\begin{array}{l}\text { Falta de comunicação e articulação entre os níveis federativos; } \\
\text { Dificuldade em desenvolver relatórios correspondentes ao diagnóstico } \\
\text { urbano e rural; } \\
\text { Falta de um banco de dados com informações atualizadas sobre o } \\
\text { saneamento básico local. }\end{array}$ \\
\cline { 2 - 4 } & Gestão Municipal & $\begin{array}{l}\text { Falta de quadro técnico especializado; } \\
\text { Falta de recursos técnico-financeiros; } \\
\text { Aplicabilidade das medidas estruturantes de gestão ao longo do tempo; } \\
\text { Capacidade do município em aderir aos programas de financiamento } \\
\text { governamentais; } \\
\text { Inaptidão municipal em aplicar indicadores expostos no PMSB; } \\
\text { Baixa capacidade de manutenção; } \\
\text { Descontinuidade política. }\end{array}$ \\
\cline { 2 - 4 } & $\begin{array}{l}\text { Participação e } \\
\text { Controle Social }\end{array}$ & $\begin{array}{l}\text { Falta de compreensão da população e dos gestores municipais em } \\
\text { relação aos problemas que só serão resolvidos a longo prazo; } \\
\text { Falta de interesse da população em participar das audiências públicas. }\end{array}$ \\
\hline
\end{tabular}

Revista Gestão e Sustentabilidade Ambiental., v. 10, n. 3, p. 174-196, set. 2021. 


\section{¿UNISUI}

\begin{tabular}{|c|c|c|}
\hline \multirow{3}{*}{ Itapirapuã } & Comunicação & $\begin{array}{l}\text { Falta de comunicação e articulação entre os níveis federativos; } \\
\text { Dificuldade em desenvolver relatórios correspondentes ao diagnóstico } \\
\text { urbano e rural; } \\
\text { Falta de um banco de dados com informações atualizadas sobre o } \\
\text { saneamento básico local. }\end{array}$ \\
\hline & Gestão Municipal & $\begin{array}{l}\text { Falta de quadro técnico especializado; } \\
\text { Falta de recursos técnico-financeiros; } \\
\text { Aplicabilidade das medidas estruturantes de gestão ao longo do tempo; } \\
\text { Capacidade do município em aderir aos programas de financiamento } \\
\text { governamentais; } \\
\text { Inaptidão municipal em aplicar indicadores expostos no PMSB; } \\
\text { Baixa capacidade de manutenção; }\end{array}$ \\
\hline & $\begin{array}{l}\text { Participação e } \\
\text { Controle Social }\end{array}$ & $\begin{array}{l}\text { Falta de compreensão da população e dos gestores municipais em } \\
\text { relação aos problemas que só serão resolvidos a longo prazo; } \\
\text { Falta de interesse da população em participar das audiências públicas. }\end{array}$ \\
\hline \multirow{3}{*}{ Mossâmedes } & Comunicação & Falta de comunicação e articulação entre os níveis federativos. \\
\hline & Gestão Municipal & Falta de quadro técnico especializado. \\
\hline & $\begin{array}{l}\text { Participação e } \\
\text { Controle Social }\end{array}$ & Falta de interesse da população em participar das audiências públicas. \\
\hline \multirow[b]{3}{*}{ Uirapuru } & Comunicação & Falta de comunicação e articulação entre os níveis federativos. \\
\hline & Gestão Municipal & Falta de quadro técnico especializado. \\
\hline & $\begin{array}{l}\text { Participação e } \\
\text { Controle Social }\end{array}$ & $\begin{array}{l}\text { Falta de conhecimento da população em relação aos componentes do } \\
\text { saneamento básico; } \\
\text { Falta de interesse da população em participar das audiências públicas. }\end{array}$ \\
\hline
\end{tabular}

Fonte: Autoras.

\section{CONSIDERAÇÕES FINAIS}

Este trabalho pretendeu identificar e analisar os dificultadores na formulação da Política Pública de Saneamento em quatro municípios goianos na percepção dos atores governamentais e não governamentais que participaram ativamente na elaboração do PMSB, preceito fundamental para a sanção municipal.

Em conformidade com o que foi relatado pelos entrevistados, os dificultadores encontrados relacionam-se a três eixos temáticos principais: comunicação; gestão municipal e controle e participação social. Verifica-se que entre os problemas relatados, a falta de quadro técnico especializado se destaca, já que compromete a aplicabilidade das medidas estruturantes de gestão ao longo do tempo e expõe a necessidade de os municípios buscarem apoio técnico externo para a elaboração dos PMSBs; outra consequência é a inaptidão dos municípios em aplicar os indicadores 
expostos no plano após a finalização dos contratos com as consultorias. Além disso, a falta de interesse da população local em participar das audiências públicas demonstra a importância da educação ambiental e política como atributo fundamental para a execução da cidadania.

A principal limitação desse trabalho deve-se ao número pequeno de municípios estudados e o fato de pertencerem a um mesmo Estado da Federação, situação que pode comprometer a representatividade do estudo em âmbito nacional.

Em contrapartida, acredita-se que esta pesquisa pode fornecer base para diversos estudos futuros, como: analisar a implementação da Política Pública de Saneamento Básico em municípios de diferentes portes; realizar estudos comparativos entre a formulação da Política de Saneamento em realidades técnicofinanceiras distintas; investigar e compreender as dificuldades encontradas pelos municípios em desenvolver bases de dados atualizados sobre os componentes do saneamento entre outros.

Julga-se por fim que este trabalho é de essencial relevância pela própria realidade vivenciada pela maioria dos municípios brasileiros no que tange à situação do saneamento básico, isto é, baixo índice de tratamento de água e esgotamento sanitário, inexistência de sistemas que tratam os resíduos sólidos e a drenagem e o manejo de águas pluviais, além da falta de limpeza urbana. Condições estas que perpetuam diversas doenças decorrentes da falta de saneamento, impactam diretamente na qualidade de vida dos cidadãos, além de impedir o crescimento e desenvolvimento das cidades de maneira sustentável.

\section{REFERÊNCIAS}

ALVES FILHO, H. T. Panorama situacional dos planos municipais de saneamento básico nos municípios do Rio Grande do Norte. [s.I.] Universidade Fderal do Rio Grande do Norte, 2016.

ANA. Conjuntura dos recursos hídricos no Brasil 2019: informe anual. Brasília: ANA, 2019. Disponível em: <http://conjuntura.ana.gov.br/static/media/conjunturacompleto.bb39ac07.pdf>.

ARRETCHE, M. Federalismo e Relações Intergovernamentais no Brasil: A Reforma de Programas Sociais. Dados - Revista de Ciências Sociais, v. 45, p. 431-458, 
2002.

ARRETCHE, M. Financiamento federal e gestão local de políticas sociais: o difícil equilíbrio entre regulação, responsabilidade e autonomia. Ciência \& Saúde Coletiva, v. 8, n. 2, p. 15, 2003.

BARBOSA, J. L. Política pública, gestão municipal e participação social na construção de uma agenda de direitos à cidade. Scripta Nova. Revista Electrónica de Geografía y Ciencias Sociales, v. 14, n. 31, p. 51, 2010.

BARDIN, L. Análise de conteúdo. $1^{\mathrm{a}}$ ed. São Paulo: Edições 70, 2016.

BRASIL. Lei no $\mathbf{1 1 . 4 4 5}$ de 5 de janeiro de 2007. Estabelece diretrizes nacionais para o saneamento básico. Diário Oficial [da República Federativa do Brasil], Brasília, DF, 08 jan.2007. Seção I, p.3., , 2007. Disponível em: <http://www.planalto.gov.br/ccivil_03/_Ato2007-2010/2007/Lei/L11445.htm>

BRASIL. Decreto n' 7.217, de 21 de junho de 2010. Regulamenta a Lei no 11.445, de 5 de janeiro de 2007, que estabelece diretrizes nacionais para o saneamento básico, e dá outras providências., , 2010. Disponível em: <http://www.planalto.gov.br/ccivil_03/_ato2007-2010/2010/decreto/d7217.htm>

BRASIL. Plansab: Plano Nacional de Saneamento Básico - Mais Saúde com Qualidade de Vida e Cidadania. Brasília. Ministério das Cidades. Secertaria Nacional de Saneamento Ambiental, 2014.2 Disponível em: <http://www.cidades.gov.br/images/stories/ArquivosSNSA/PlanSaB/plansab_texto_e ditado_para_download.pdf>

BRASIL. Panorama dos Planos Municipais de Saneamento Básico no Brasil. Brasília. Ministério das Cidades. Secretaria Nacional de Saneamento Ambiental, 2017. Disponível em: <http://www.cidades.gov.br/images/stories/ArquivosSNSA/Arquivos_PDF/panorama_ planos_municipais_de_saneamento_basico.pdf>

BRASIL. Sistema Nacional de Informações sobre Saneamento: $24^{\circ}$ Diagnóstico dos Serviços de Água e Esgotos. Brasília. Ministério do Desenvolvimento Regional. Secretaria Nacional de Saneamento, 2018a. Disponível em: <http://www.snis.gov.br/downloads/diagnosticos/ae/2018/Diagnostico_AE2018.pdf>

BRASIL. Sistema Nacional de Informações sobre Saneamento. Disponível em: <http://www.snis.gov.br/>. Acesso em: 24 maio. 2020b.

BRASIL. Lei no 14.026, de 15 de julho de 2020. Atualiza o marco legal do saneamento básico e altera a Lei no 9.984, de 17 de julho de 2000, para atribuir à Agência Nacional de Águas e Saneamento Básico (ANA) competência para editar normas de referência sobre o serviço de saneamento, a Lei $n^{\circ} 10.768$, d, 2020. Disponível em: <https://legis.senado.leg.br/norma/32462863/publicacao/32491972>

CARVALHO, M. C. Assistência social: reflexões sobre a política e sua regulação. Um modo singular de produzir política. Serviço Social \& Sociedade, v. 87, p. 123-131, 2006. 
DOURADO, L. F. Sistema Nacional de Educação, Federalismo e os obstáculos ao direito à educação básica. Educação \& Sociedade, v. 34, n. 124, p. 761-785, 2013.

FUNASA. Termo de Referência para a Elaboração dos Planos Municipais de Saneamento Básico. Brasília. Ministério da Saúde. Fundação Nacional de Saúde, , 2012. Disponível em: <http://www.funasa.gov.br/site/wpcontent/uploads/2012/04/2b_TR_PMSB_V2012.pdf>

FUNDAÇÃO NACIONAL DE SAÚDE. Orientações Metodológicas para Programa de Educação Ambiental em Saneamento para Pequenos Municípios: Caderno de orientações: Caderno 1. Brasília. Ministério da Saúde. Fundação Nacional de Saúde, 2014. Disponível em: <http://www.funasa.gov.br/site/wpcontent/files_mf/orient_ed_sa_caderno1.pdf>

HELLER, L. Gestão dos serviços. In: Abastecimento de água para consumo humano. 2. ed. Belo Horizonte: UFMG, 2010. p. 829-855.

HOWLLET, M.; RAMESH, M.; PERL, A. Política pública: Seus ciclos e subsistemas - uma abordagem integral. 3. ed. Rio de Janeiro: Elsevier, 2013.

IBGE. Brasil/Goiás - Cidades e Estados. Disponível em: <https://www.ibge.gov.br/cidades-e-estados/go.html>. Acesso em: 20 abr. 2020.

JACOBI, P. Educação ambiental, cidadania e sustentabilidade. Cadernos de Pesquisa, n. 118, p. 189-205, 2003.

LIMANA, A. O Processo de Descentralização Política-Administrativa no Brasil. Scripta Nova. Revista Electrónica de Geografía y Ciencias Sociales, v. 45, n. 21, 1999.

LISBOA, S. S.; HELLER, L.; SILVEIRA, R. B. Desafios do planejamento municipal de saneamento basico em municipios de pequeno porte: a percepcão dos gestores. Engenharia Sanitaria e Ambiental, v. 18, n. 4, p. 341-348, 2013.

MORAES, L. R. S. Política e plano municipal de saneamento básico: aportes conceituais e metodológicos. In: Lei Nacional de Saneamento: perspectivas para as políticas e a gestão dos serviços públicos. Brasília: Ministério das Cidades. Secretaria Nacional de Saneamento Ambiental, 2009. p. 31-53.

NOGUEIRA, F. A. Continuidade e Descontinuidade Administrativa em Governos Locais: Fatores que sustentam a ação pública ao longo dos anos. [s.l.] Fundação Getúlio Vargas, 2006.

PEREIRA, T. S. T. Conteúdo e metodologia dos planos municipais de saneamento básico: um olhar para 18 casos no Brasil. Brasília: Fundação Oswaldo Cruz, 2012.

QUEIROZ, G. Os desafios para a implantação dos planos municipais de saneamento. Brasília. Ministério da Saúde. Funasa, 2014. Disponível em: <http://slideplayer.com.br/slide/2531588/>

REIGOTA, M. O que é educação ambiental. São Paulo: Editora Brasiliense, 2017.

SAMPIERI, R. H.; CALLADO, C. F.; LUCIO, M. P. B. Metodologia de pesquisa. 5. 


\section{sunisul}

ed. Porto Alegre: Pense, 2013.

SOARES, B. R. Planos diretores em municípios de pequeno porte: reflexões a partir de experiências multidisciplinares*. Revista Formação, v. 2, n. 15, p. 13-24, 2008.

SOUZA, C. Políticas públicas: uma revisão da literatura. Sociologias, v. 8, p. 20-45, 2006.

SOUZA, H. Y.; SECCHI, L. Extinção de políticas públicas: síntese teórica sobre a fase esquecida do police cycle. Cadernos Gestão Pública e Cidadania, v. 20, n. 66, p. 75-93, 2015.

TILLY, C. Big Structures, Large Processes, Huge Comparisons. New York: Russell Sage Foundation; Edition Unstated edition, 1989.

VASCONCELOS, P. T. A audiência pública como instrumento de participação popular na avaliação do estudo de impacto ambiental. [s.l.] Universidade Federal de Pernambuco, 2002. 